\title{
Does employee ReMuneration dispersion in the South African ECONOMY ENHANCE LABOUR PRODUCTIVITY? THE GAUTENG MANUFACTURING INDUSTRY AS A CASE STUDY
}

Author:

Gerhardus van $\mathrm{Zyl}^{1}$

\section{Affiliation:}

${ }^{1}$ Department of Economics and Econometrics,

University of Johannesburg, South Africa

\section{Correspondence to:}

Gerhardus van Zyl

email:

hardusvz@uj.ac.za

Postal address:

Department of Economics and Econometrics,

University of Johannesburg, PO Box 10152, Aston Manor 1630, South Africa

\section{Keywords:}

employee-remuneration gap; labour productivity employee remuneration gap-labour productivity (ERGLP) indicator coefficient; skill levels; employee characteristics; business or economic uncertainty

Dates:

Received: 09 Mar 2010

Accepted: 30 Jul 2010

Published: 11 Nov. 2010

How to cite this article: Van Zyl, G. (2010). Does employee remuneration dispersion in the South African economy enhances labour productivity? The Gauteng manufacturing industry as a case study. $S A$ Journal of Human Resource Management/SA Tydskrif vir Menslikehulpbronbestuur, 8(1), Art. \#286, 5 pages. DOI: 10.4102/sajhrm.v8i1.286

This article is available at: http://www.sajhrm.co.za
(C) 2010. The Authors. Licensee: OpenJournals Publishing. This work is licensed under the Creative Commons Attribution License.
Orientation: The paper dealt with the application of a suitable econometric estimation model or procedure to measure the relation between employee-remuneration gaps and labour productivity in the Gauteng manufacturing industry.

Research purpose: The aim of the article was to estimate the sign and magnitude of the relation between employee-remuneration gaps and labour productivity econometrically. The Gauteng manufacturing sector was used as a case study.

Motivation for the study: The empirical research was deemed necessary given the current important debate on the perceived impact and fairness of expanding employee-remuneration gaps in the South African workplace. International studies have been conducted on this particular topic but very limited empirical research has been published regarding the South African situation.

Research design, approach and method: A log-linear two-step OLS estimation was used to estimate the sign and magnitude of the relation between employee-remuneration gaps and labour productivity. Employee remuneration gap-labour productivity (ERGLP) indicator coefficients were estimated, taking into consideration employee characteristics, skill levels and business or economic uncertainty.

Main findings: The signs of the ERGLP indicator coefficients were positive in terms of all the categories, indicating a positive relation between employment-remuneration gaps and labour productivity (at varying magnitudes). The squared ERGLP indicator coefficients confirmed the existence of diminishing marginal productivity characteristics after an optimal employeeremuneration gap level.

Practical/managerial implications: It is recommended that, given the unionised nature of the lower-skilled employee segment in South Africa, greater labour-productivity gains for organisations would stem from a more dispersed employee-remuneration regime for the higherskilled employee segment (albeit in a less uncertain business or economic environment).

Contribution/value-add: An econometric estimation procedure that can be applied to the measurement of the productivity gains of employee-remuneration gaps for different industries in the South African economy was established.

\section{INTRODUCTION}

The aim of the article was to apply a South African industry characteristic-focused econometric model (procedure) (1) to estimate the sign and magnitude of the link between employee-remuneration gaps and labour productivity and (2) to determine possible productivity gains generated by employeeremuneration gaps.

There is currently an important general debate in South Africa (among employer organisations, labour unions, politicians etc.) on the size and fairness of perceived employee-remuneration gaps among the different employment levels in organisations. Labour unions, in particular, are of the opinion that these remuneration gaps are expanding and that the situation constitutes a major threat to job creation and the fair distribution of income in the workplace and the economy as a whole. Employer organisations, however, argue that employee-remuneration gaps are, in the main, the result of the shortages of higher-skilled employees in the workplace and differences in labourproductivity levels between the different employee segments.

The aim of the literature study was purely the identification of all the important variables that drive the employee remuneration gap-labour productivity (ERGLP) relation to specify the econometric model and estimation procedure efficiently and correctly.

Research results on the relation between employee-remuneration gaps and labour productivity vary.

One school of thought (Benito, 2000; Mahy, Rycx \& Volral, 2009; Turner \& Jackson, 2009) argues for the existence of a positive link between employee-remuneration gaps and labour productivity, in that the greater the employee-remuneration gap, the higher the level of labour productivity. Reasons in support of this argument are that (1) human effort is enhanced if a more differentiated remuneration structure is adopted (Turner \& Jackson, 2009) and (2) high levels of labour productivity are normally rewarded with higher remuneration structures (Benito, 2000). Martins (2008) and Mahy, Rycx and Volral (2009) were of the opinion that this positive relation between employee-remuneration gaps 
and labour productivity is not infinite but that it does adhere to some form of increasing and diminishing marginal productivity characteristics: the positive relation reaches an optimal level but, with further increases in employee-remuneration gaps, the relation becomes negative. A study by Winter-Ebner and Zweimuller (1999) indicated that the positive relation between employee-remuneration gaps and labour productivity is more prevalent for production workers (so-called blue-collar employees) than for managerial or administrative employees (so-called white-collar employees).

The second school of thought (Brown \& Medoff, 1989; Erdill \& Yetkiner, 2001; Hibbs \& Locking, 2000; Lopez-Bazo \& Motellon, 2009) argues that there is a negative relation between employeeremuneration gaps and labour productivity. The following reasons are given for this negative relation:

- smaller remuneration gaps result in a greater level of employee cohesion and therefore an improved level of labour productivity (Brown \& Medoff, 1989; Erdill \& Yetkiner, 2001)

- if employees feel that their real remuneration is less than what they define as a fair remuneration package, labour productivity decreases (Genre, Momferatou \& Mourre, 2005)

- variation in labour productivity necessitates a lessdispersed employee-remuneration distribution (Hibbs \& Locking, 2000; Ho \& Yap, 2001)

Irrespective of whether the relation between employeeremuneration gaps and labour productivity is positive or negative, however, all the research findings clearly indicate three important aspects that need to be considered, namely (1) employee characteristics, (2) the difference in the skill levels of employee segments and (3) the level of uncertainty in the business or economic environment in which a particular employer operates.

Erdill and Yetkiner (2001) indicated that employee characteristics had to be taken into consideration and that the link between employee-remuneration gaps and labour productivity depends on an employee's position in the remuneration structure. Jirjahn and Kraft (2007) reported that the labour-relations regime and the type of incentive schemes play an important role in determining the sign and magnitude of the link between employee-remuneration gaps and labour productivity. It has furthermore been argued that differences in (1) the size and kind of ownership of organisations (Beaumont \& Harris, 2003) and (2) the kind of management regime (Belfield \& Marsden, 2003) also impact on the relation between employee-remuneration gaps and labour productivity. Lazear (1995) came to a very interesting conclusion: he argued that (1) the remuneration regimes of employers should be tailored to take the characteristics of their workforce into account and (2) less-dispersed employee-remuneration gaps were preferable at management level.

In terms of skill levels, Genre et al. (2005) and Lallermond (2007) indicated that smaller remuneration gaps are required for higher-skilled employees if labour productivity is to be enhanced. Heyman (2005), Prendergast (2002) and Turner and Jackson (2009), however, concluded that the relationship between remuneration gaps and labour productivity is stronger when employees are more skilled. According to them, the reason is that the remuneration regime for higher-skilled employees is linked to firm performance and that more dispersed employeeremuneration gaps induce these employees to act in an optimal manner (with higher levels of productivity). Foss and Laursen (2005) and Mahy et al. (2009) indicated that employeeremuneration gaps for less-skilled workers should be smaller, as limited performance-linked regimes are needed to enhance labour productivity.

Uncertainty in the business or economic environment impacts on the sign and magnitude of the link between employee- remuneration gaps and labour productivity. Brown and Medoff (1989), Prendergast (2002) and Mahy et al. (2009) confirmed the existence of a positive relation between uncertainty and the dispersion of employee-remuneration gaps. The basic argument is that performance-linked remuneration regimes (which entail more dispersed remuneration gaps) are more prominent when business or economic uncertainty is high. Fagio, Salvaness and Van Reenen (2007), however, argued that, in a highly uncertain business or economic environment, the link between employee-remuneration gaps and labour productivity should be weaker simply because employees regard performancelinked remuneration regimes as unfair (since they have less control over their own labour-output relation).

From the literature study, it was concluded that the specification of the econometric model should include (1) employee characteristics (such as age, sex, job description, union affiliation and employee category), (2) different skill levels and (3) the level of business or economic uncertainty.

The econometric-estimation procedure or model can be applied for the measurement of the productivity gains of employeeremuneration gaps for different industries in the South African economy. More specifically, this econometric-estimation procedure or model captures all the important industry-specific characteristics from which the ERGLP coefficients can be derived for different industries in the South African economy.

In the rest of the article, (1) detailed attention is given to the research design, in which a suitable econometric model is applied to the applicable data (sourced from organisations in the Gauteng manufacturing industry) and (2) the results and practical implications of the estimated ERGLP coefficients are analysed and discussed.

\section{RESEARCH DESIGN}

\section{Research approach}

The research approach comprised three distinct steps. Firstly, a suitable econometric model needed to be specified to capture all the variables that have an impact on the sign and magnitude of the link between employee-remuneration gaps and labour productivity. Secondly, the correct sample of organisations in the South African manufacturing industry needed to be determined and the required data needed to be collected from this sample (after which the data needed to be statistically and econometrically calibrated). The last step entailed the econometric estimation of the relation between employeeremuneration gaps and labour productivity.

The suitable econometric model was specifically designed for the derivation of the ERGLP coefficients that estimate the sign and magnitude of the relation between employee-remuneration gaps and labour productivity, taking the impact of employee characteristics, skill levels and the level of business or economic uncertainty into consideration.

\section{Research method}

\section{Measuring instrument (econometric model)}

In a study on the impact of wage dispersion on productivity in Belgian firms, Mahy et al. (2009) used the Winter-Ebner and Zweimuller (1999) model. The major contribution of the Mahy et al. study is the empirical estimation of the effect of firm uncertainty on wage dispersion.

In order to facilitate an international comparison of the results of this particular study with a similar international study, the Mahy et al. (2009) estimation procedure of the Winter-Ebner and Zweimuller model was applied in this particular study. The model and the required data-collection procedure were adapted to meet South African conditions and then used to estimate the sign and magnitude of the relation between 
employee-remuneration gaps and labour productivity. The model was specified in such a manner that the South African characteristics of the employees (such as age, sex, job description, labour-union affiliation and employee job category), the different skill levels and business or economic uncertainty (the net operating surplus of organisations taken as the estimator) were taken into consideration. The relation between employee-remuneration gaps and labour productivity was therefore a conditional one. In technical terms, the model estimated a conditional employee ERGLP indicator coefficient. The specification of the model allowed for the estimation of the ERGLP indicator coefficient between similar and different employee categories (characteristics and skill levels) and for the different business or economic-uncertainty levels.

The model was basically a two-step ordinary least square (OLS) estimation.

The first step pertained to the estimation of the relation between employee characteristics and the average monthly remuneration per employee. A log-linear estimation of the average monthly remuneration based on employee characteristics was therefore done for each organisation in the sample group.

$\operatorname{Ln} \mathrm{r}_{n m}=\beta_{0}+\mathrm{c}_{n m} \beta_{1}+\varepsilon_{n m}$

In equation $1, \mathrm{r}_{n m}$ denotes the average monthly remuneration of employee $n$ in organisation $m, \mathrm{c}_{n m}$ represents the vector that concerns employee and skills characteristics and $\varepsilon_{n m}$ is simply the error term.

The second step involved the specification of the labourproductivity equation. To estimate this productivity equation, the standard deviations of the estimated residuals of all the regressions done in step 1 were used as a measure of the employee-remuneration gap dispersion.

$L n \operatorname{prod}_{m}=\alpha_{0}+\alpha_{1} \sigma_{\mathrm{m}}\left(+\alpha_{2} \sigma_{m}^{2}\right)+\mathrm{x}_{m} \alpha_{3}+\mathrm{z}_{m} \alpha_{4}+\mathrm{V}_{m}$

In equation 2, prod represents the average labour productivity of organisation $m(L n$ of the value added per employee is used as a proxy for $L n \operatorname{prod}_{w}$ ), $\sigma_{m}$ is the ERGLP indicator coefficient (it is also specified in quadratic format simply to test for increasing and diminishing marginal productivity characteristics), $x_{m}$ is the aggregated employee characteristics of firm $m, z$ contains information on business or economic uncertainty (variations in net operating surplus were used as the proxy) and $\mathrm{v}_{m}$ is simply the error term.

Equation 2 was run separately for each organisation. To cater for simultaneity, Equation 2 was estimated with the log of the value added per employee (defined as operating surplus divided by the number of employees) for $n$-years instead of $n$ - 1 years. It was assumed that the value added of year $n$ does not influence the remuneration structure of year $n-1$.

The results of three final estimations were reported. The first estimation concerned the general specification in which the ERGLP indicator coefficient was estimated on the basis that all the employee characteristics were, in an econometric sense of the word, controlled. In the second estimation, the ERGLP indicator coefficients were specifically estimated for the magnitude of the different skill levels (higher-skilled and lower-skilled employees). In the third estimation, the ERGLP indicator coefficient was specifically estimated for the level of business or economic uncertainty.

\section{Research procedure}

The data collection process was executed in three stages. In the first stage, the data required by the model specification were identified (the results of the literature study were of the utmost importance in this regard). In the second stage, the sample group of organisations needed to collect the data from was established and statistically validated (more specifically, the required size of the sample group). In the third stage, the standard deviations of the data collected from the sample group were calculated for use in the estimation process. Normality tests were performed for estimation purposes.

As was the case with the Mahy et al. study (2009), the International Standard Classification of Occupations (ISCO-88) was used to identify the employee categories. The category A classification consisted of senior officials and managers, professionals and associate professionals, technicians, clerks, service workers and shop and market-sales workers. For the purposes of this study, this category was referred to as the more-skilled employee segment. The category B classification consisted of craft and related-trade workers, plant and machine operators and assemblers and elementary occupations. For the purposes of this study, this category was referred to as the less-skilled employee segment. The data that were collected included the size of the workforce per organisation and the percentage size of each category (both A and B) per organisation.

In terms of employee characteristics, skill levels and employee remuneration, data for two financial years were collected on:

- age

- $\operatorname{sex}(\%$ male and $\%$ female)

- training or educational levels

- labour-union affiliation

- tenure and gross monthly employee remuneration.

With regard to training or educational levels, the following three categories were identified, (1) lower-secondary education (Grade 9 and lower), (2) upper-secondary education (Grades 10-12) and (3) tertiary education. It is also important to note that the gross remuneration of hourly-paid employees was converted into a gross monthly-remuneration equivalent.

Data on the operating surplus (and the variation thereof) of each organisation in the sample group for both 2007 and 2008 needed to be collected (1) as an indicator of business or economic uncertainty (greater variation of the operating surplus reflects greater uncertainty) and (2) to calculate annual value added per employee.

\section{Research sample}

Given the significant size of the manufacturing industry in Gauteng (relative to the manufacturing sectors of the other provinces in South Africa), it was decided to sample a representative number of all kinds of manufacturing firms located in Gauteng. A list of all the manufacturing companies in Gauteng, with their contact details, was obtained from the Manufacturing, Engineering and Related Services SETA. It was also the aim of the data-collection process to ensure that a spread of firms throughout the different segments of the manufacturing industry was included. It is important to note that, because of the large number of required data observations, it was decided to include only firms with more than 150 employees. The sample size based on the aforementioned constraint and the statistical validation was 209 firms. The response rate was excellent and all the 192 firms responded and supplied the required data.

The mean values (the standard deviations, $S_{D^{\prime}}$ are indicated in brackets) of the data collected on the estimation variables were:

- size of the firm: $225.71\left(S_{D} 182.93\right)$ employees

- category A employees: $40.88 \%\left(S_{D} 19.87\right)$

- category B employees: $59.12 \%\left(S_{D} 39.12\right)$

- age: $31.12\left(S_{D} 3.25\right)$ years

- percentage male: $63.78 \%\left(S_{D} 28.22\right)$ and percentage female: $36.22 \%\left(S_{D} 31.15\right)$

- lower-secondary educated employees: $42.25 \%\left(S_{D} 36.21\right)$, upper-secondary educated employees: $40.65 \%\left(S_{D} 32.58\right)$ and tertiary education: $17.10 \%\left(S_{D} 14.11\right)$

- gross monthly wage: R7424 $\left(S_{D} 893\right)$

- annual value added per employee: R758 $385\left(S_{D} 243567\right)$. 


\section{RESULTS}

In terms of the general specification, the ERGLP indicator coefficient was $2923.80(0.82)$ and the squared ERGLP indicator coefficient -3317.11 (2.1). (The standard errors are shown in brackets, the results were significant at a $5 \%$ confidence level and the adjusted $R^{2}$ was 0.61 .) The positive sign and the magnitude of the ERGLP indicator coefficient clearly proved a significant positive relation between employee-remuneration gaps and labour productivity for the sample group. The negative sign of the squared ERGLP indicator coefficient confirmed the existence of diminishing marginal labour productivity beyond an optimal level of employee-remuneration gaps. This simply means that excessive employee-remuneration gaps are harmful to labour-productivity gains. To cater for the possibility of simultaneity in the general specification, a one-period lead was introduced into the OLS estimation. The resultant ERGLP indicator coefficient of 2743.56 (1.03) and the squared ERGLP indicator coefficient of -2987.11 (2.42) again confirmed the significant positive relation between employee-remuneration gaps and labour productivity as well as the existence of diminishing labour-productivity characteristics beyond an optimal level of employee-remuneration gap dispersion.

In the second estimation, the ERGLP indicator coefficient was estimated for the different skill levels. As indicated previously, category A was assumed to be the more-skilled employee segment and category B the less-skilled employee segment. These two skill categories were further subdivided into large and small subcategories. The aim was simply to determine whether the ERGLP indicator coefficient differed for (1) organisations that have a large component of lower-skilled employees versus organisations that have a small component of lower-skilled employees and (2) organisations that have a large component of higher-skilled employees versus organisations that have a small component of higher-skilled employees. To differentiate between the large and small components, the mean values were used. The small component was defined as less than the mean and the large component as greater than the mean. The estimated ERGLP indicator coefficients are listed in Table 1.

The negative-squared ERGLP indicator coefficient estimates of all the different categories suggested strong diminishing marginal labour-productivity characteristics. Excessive employee-remuneration gaps (after an optimal employeeremuneration gap level) would have a strong negative effect on labour productivity should the remuneration-gap dispersion go beyond that optimal level. This applied to both lowerskilled and higher-skilled employees. It is interesting to note that the magnitude of the positive relation between employeeremuneration gaps and labour productivity was higher for higher-skilled employees than for lower-skilled employees. It was especially very high in the higher-skilled or largeemployee segment. This result was a plausible confirmation that performance-linked remuneration regimes for the higherskilled employee segment had a strong positive impact on labour productivity. It was also interesting to note that the positive ERGLP indicator coefficient estimates for the lowerskilled or large and lower-skilled or small components were very similar, meaning that the relative magnitude of the positive link between employee-remuneration gaps and labour productivity was the same irrespective of the size of the lowerskilled employee component.

Lastly, ERGLP indicator coefficients were estimated for the impact of business or economic uncertainty (measured as variations in operating surplus). It was decided to differentiate between high levels of uncertainty and low levels of uncertainty. The differentiation between these two subcategories was based on the mean value of the variation in operating surplus. Low risk was defined as variation in operating surplus falling below the mean value and high risk was defined as variation in
TABLE 1

Employee remuneration gap-labour productivity indicator coefficients for the different skill levels

\begin{tabular}{lll}
\hline Category & $\begin{array}{l}\text { ERGLP indicator } \\
\text { coefficient }\end{array}$ & $\begin{array}{l}\text { Squared ERGLP indicator } \\
\text { coefficient }\end{array}$ \\
\hline Lower-skilled/large & 1720 & -6170 \\
& $(0.89)$ & $(2.51)$ \\
Lower-skilled/small & 1911 & -8350 \\
& $(1.74)$ & $(3.43)$ \\
Higher-skilled/large & 5430 & -8120 \\
& $(1.73)$ & $(3.24)$ \\
Higher-skilled/small & 2950 & -4730 \\
& $(0.81)$ & $(1.73)$ \\
\hline Source: Own estimations & &
\end{tabular}

The standard errors are listed in brackets, the results are significant at a $5 \%$ confidence level and the adjusted $\mathrm{R}^{2}$ was 0.62 .

TABLE 2

Employee remuneration gap-labour productivity indicator coefficients for the different levels of business or economic uncertainty

\begin{tabular}{lll}
\hline Category & $\begin{array}{l}\text { ERGLP indicator } \\
\text { coefficient }\end{array}$ & $\begin{array}{l}\text { Squared ERGLP indicator } \\
\text { coefficient }\end{array}$ \\
\hline High uncertainty & +3718 & -4968 \\
& $(0.93)$ & $(2.77)$ \\
Low uncertainty & +4221 & -5111 \\
& $(1.36)$ & $(2.45)$ \\
\hline
\end{tabular}

Source: Own estimations

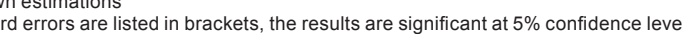
and the adjusted $R^{2}$ was 0.65 .

operating surplus falling above the mean value. The estimated ERGLP and squared ERGLP indicator coefficients are listed in Table 2.

The results were interesting in the sense that the ERGLP indicator coefficient was greater in a low uncertain environment than in a highly uncertain environment. This indicated a stronger positive link between employee-remuneration gaps and labour productivity in a more certain business or economic environment. A plausible reason for this is that performancelinked regimes seem to impact less on employee effort in a highly uncertain business or economic environment because employees might feel that they have less control over their effort-output relation. Irrespective of the level of business or economic uncertainty, the negative sign and the magnitude of both the squared ERGLP indicator coefficients showed a strong diminishing marginal labour-productivity characteristic beyond an optimal employee-remuneration gap level.

\section{DISCUSSION}

The aim of the article was to estimate the sign and magnitude of the link between employee-remuneration gaps and labour productivity econometrically.

The results of the study confirm the existence of a positive relation between employee-remuneration gaps and labour productivity but with the provision that this positive relation is not infinite. After an optimal employee-remuneration gap level, diminishing marginal labour-productivity characteristics kick in and the relation becomes negative. These findings apply to all the various differentiations in employee characteristics, different skill levels and the nature of business or economic uncertainty levels. The results indicate that employee effort could be enhanced if a more differentiated remuneration regime (performance-linked) were adopted. This is especially true for the higher-skilled employee component.

It is interesting to note that the employee-remuneration gap dispersion impact on labour productivity is less in the lowerskilled employee segment than in the higher-skilled employee segment. A plausible reason for this might be that the lowerskilled segment is much more unionised than the higherskilled segment. This is also underpinned by the fact that (1) the magnitude of the ERGLP indicator coefficients is very similar for the two subsections (both large and small) of the 
lower-skilled employee segment and (2) the magnitude of the ERGLP indicator coefficients is much stronger for the higherskilled employee segment than for the lower-skilled employee segment.

In terms of the impact of business or economic uncertainty, the results of this study indicate that the positive relation between employee-remuneration gaps and labour productivity is weaker in a highly uncertain business or economic environment (underpinned by the fact that the ERGLP indicator coefficient is smaller in a more uncertain business or economic environment).

The results of this study support the point of view that, given the unionised nature of the lower-skilled employee segment, greater labour-productivity gains for organisations would stem from a more dispersed employee-remuneration gap regime for the higher-skilled employee segment (albeit in a less uncertain business or economic environment).

Further possible extensions of this study are twofold. Firstly, it would be valuable to develop an econometric instrument or technique that could determine the actual optimal employeeremuneration gaps for the different employee categories before diminishing marginal productivity characteristics kick in. Secondly, it would be worthwhile conducting the same study for different industries to determine whether there are industry differences in ERGLP indicator coefficients.

\section{REFERENCES}

Beaumont, P.B., \& Harris, R.I.D. (2003). Internal wage structure and organisational performance. British Journal of Industrial Relations, 41(1), 53-70.

Belfield, R., \& Marsden, D. (2003). Performance pay, monitoring environments and establishment performance. International Journal of Manpower, 24(4), 452-471.

Benito, A. (2000). Inter-industry wage differentials in Great Britain. Oxford Bulletin of Economics and Statistics, 62, 727-746.

Brown, C., \& Medoff, J. (1989). The employer size-wage effect. Journal of Political Economy, 97, 1027-1059.

Erdill, A., \& Yetkiner, H. (2001). A comparative analysis of inter-industry wage differentials: Industrialized versus developing countries. Applied Economics, 33, 1639-1648.

Faggio, G., Salvaness, K.G., \& Van Reenen, J. (2007). Understanding wage and productivity dispersion in the United Kingdom. VOX Occational Paper Series, (742).
Foss, N.J., \& Laursen, K. (2005). Performance pay, delegation and multi-tasking under uncertainty and innovativeness: An empirical investigation. Journal of Economic Behavior $\mathcal{E}$ Organization, 58(2), 246-276.

Genre, V., Momferatou, D., \& Mourre, G. (2005). Wage diversity in the Euro area: An overview of labour cost differentials across industries. Occasional Paper Series, (24), European Central Bank.

Heyman, F. (2005). Pay inequality and firm performance: Evidence from matched employer-employee data. Applied Economics, 37(11), 1313-1327.

Hibbs, D.A., \& Locking, H. (2000). Wage dispersion and productive efficiency: Evidence for Sweden. Journal of Labor Economics, 18(4), 755-782.

Ho, L., \& Yap, S. (2001). Link between wages and labour productivity: An analysis of the Malaysian Journal of Economics. The Malaysian Journal of Economic Studies, 38, $1-22$.

Jirjahn, U., \& Kraft, K. (2007). Intra-firm wage dispersion and firm performance - Is there a uniform relationship? Kyklos, 60(2), 231-253.

Lallermond, T. (2007). Wage structure and firm productivity in Belgium. Working paper 12978, National Bureau of Economic Research, Cambridge.

Lazear, E.P. (1995). Personnel economics. Cambridge (Mass): MIT Press.

Lopez-Bazo, E., \& Motellon, E. (2009). Human capital and regional wage gaps. Working paper no. 24, Research Institute of Applied Economics, University of Barcelona, Barcelona.

Mahy, B., Rycx, F., \& Volral, M. (2009). Wage dispersion and firm productivity in different working environments. IZA working paper no. 4044, Social Science Research Network, New York.

Martins, P.S. (2008). Dispersion in wage premiums and firm performance. Economics Letters, 101(1), 63-65.

Prendergast, C. (2002). The tenuous trade-off between risk and incentives. Journal of Political Economy, 110(5), 1071-1102.

Turner, H.A., \& Jackson, D.A. (2009). On the stability of wage differences and productivity-based wage policies: An international analysis. British Journal of Industrial Relations, 7(1), 1-18.

Winter-Ebner, R., \& Zweimuller, J. (1999). Intra-firm wage dispersion and firm performance. Kyklos, 52(4), 555-572. 